\title{
Molecular Design of Sugar-Based Polyurethanes
}

\author{
Min-Yen Lu, ${ }^{1}$ Attila Surányi, ${ }^{1}$ Béla Viskolcz, ${ }^{1}$ Béla Fiser ${ }^{1,2, *}$
}

\footnotetext{
${ }^{1}$ Computational Molecular Design Research Group, Institute of Chemistry, Faculty of Material Science and Engineering, University of Miskolc, Miskolc, Egyetemváros, 3515, Hungary

2 Ferenc Rákóczi II. Transcarpathian Hungarian Institute, Beregszász, Transcarpathia, 90200, Ukraine

${ }^{*}$ Corresponding author's e-mail address: fiser.bela@gmail.com
}

RECEIVED: March 13, 2018 * REVISED: May 6, $2018 *$ ACCEPTED: May 8, 2018

Abstract: Polyurethane (PUs) are present in many aspects of everyday lives such as the rigid foam insulation panel in construction, seat cushion in automotive and elastomeric materials in medical industries. Conventional PUs are made from petrochemical based starting materials which raised severe health and environmental concerns. The substitution of petro-based polyols with carbohydrate polyols have shown to improve biodegradability and mechanical properties of PUs. Reaction pathways were examined with density functional theory to design novel environmental friendly polyurethanes. Based on the calculated thermodynamic properties, the reactivity of sugars towards isocyanates was compared. Fructose was found to be the most reactive as the corresponding fructose-isocyanate reaction has the lowest energy barrier of $135.6 \mathrm{~kJ} / \mathrm{mol}$. Therefore, the results obtained have encouraged the synthesis of fructose-based polyurethane foam. The synthesis was successful, and the produced fully fructose-based foam was stable with minimal sign of shrinkage.

Keywords: Polyurethanes, Natural Polyols, Carbohydrates, Density Functional Theory, Molecular Modelling.

\section{INTRODUCTION}

$\mathbf{P}$ OLYURETHANES (PUs) are polymers (Figure 1) made by reacting diisocyanates with polyols to form various versatile materials such as heat insulators in construction, seat cushion in automotives and elastomeric materials in medical applications. ${ }^{[1]}$ Conventional PUs are made from petrochemical based starting materials which raised severe health and environmental concerns.[2] Thus, intensive research and development has been carried out to prepare polyurethanes based on natural polyols that can be sustainable for production.

Consequently, several approaches have been taken to create more environmental friendly polyurethanes such as searching for new reaction pathway or substituting petro-based polyols with renewable resources. In terms of

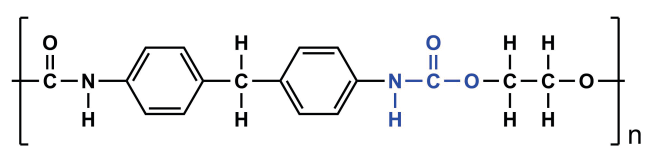

Figure 1. Structure of conventional polyurethane (PU). The urethane linkage indicated in blue. exploring new reaction pathway, research and development have been carried out to prepare nonisocyanate polyurethanes (NIPU). One example is the commercially available non-isocyanate Green Polyurethane ${ }^{\mathrm{TM}}$ coatings done by Figovsky et al. ${ }^{[3,4]}$ These coatings are product of hydroxyurethane modifiers (HUM) created between a primary amine and a monocyclic carbonate. Although this pathway successfully discards the toxic isocyanates in the reaction, the end-product is a polyhydroxyurethane instead of a polyurethane. ${ }^{[5-8]}$ Thus, a growing interest is devoted to chemicals deriving from renewable resources such as natural oil, carbohydrates. Natural polymers show the advantages of bio-degradability, bio-compatibility, non-toxicity, high reactivity, low cost, easy availability. ${ }^{[9,10]}$

Incorporation of a natural component as a filler into a synthetic polymer structure to make composites is a technique to provide better mechanical support and enhance degradation through additional crosslinking. ${ }^{[11]}$ Cao et al. ${ }^{[12]}$ incorporated cellulose nanocrystals (CNC) into waterborne polyurethanes to prepare thermoplastic nanocomposites which could significantly improve the interfacial adhesion between matrix and filler. In addition, 
more research on natural oil polyol continue to be carried out for specific applications as PUs based on them show outstanding properties. In a recent study, Oliviero et al. [13] synthesized bio-based flexible PU foams with MDI and succinium ${ }^{\mathrm{TM}}$ polyl which possess improved sound insulation at high frequency, mechanical and acoustic performances appropriate for automotive and aircraft industries. Among all ecofriendly feedstocks, dicarboxylic acids have attracted particular interest as raw materials to produce polyols.

Several carbohydrates including polysaccharides such as starch, chitin, chitosan, cellulose, and proteins are examples that are broadly used in biomedical field such as wound healing or artificial tissue scaffolds which require biodegradation. ${ }^{[14]}$ This concept can be applied to design degradable polyurethane as well. Although many studies have been done on NOPs, there are little or no information about the substitution of cellulose or starch derivatives for conventional polyether polyol (PEPs). In the study done by David et al.,, ${ }^{[15]}$ carbohydrates such as carboxy-methyl cellulose sodium salt (CMC-Na), cellulose acetate (CA), 2-hydroxyethyl cellulose (2-HEC) can successfully replace polyether polyols in the bio-PU foam system with up to $30 \%$ of CMC-Na, $10 \%$ of CA, $10 \%$ of HEC substitution. It was found that higher content of substitution resulted in heterogeneous structure of the foams.

In the work of Seckin et al., ${ }^{[16]}$ novel crosslinked PU films were successfully synthesized by using MDI, 1,2ethanediol and various composition ( $1 \%, 3 \%, 5 \%, 10 \%)$ of fructose. The PU film could be used as $\mathrm{pH}$ determination because of its strong adherence and chemical stability. Increasing fructose content leads to more crosslinking of polymer chains and higher Tg values. It was also shown that the introduction of polysaccharide into PU chains provides PU with higher capability to degradation. It improves the adhesion of microorganisms such as $B$. subtilis to the surface due to its hydrophilicity nature. ${ }^{[17]}$

Furthermore, Savelyev et al.[18] investigated the degradability of elastic PU foams based on various disaccharides including glucose, lactose, maltose and sucrose. It was found that they undergo enhanced alkaline/acid hydrolysis when incubated in soil because the hydrophilic character of sugars improves the adhesion of microorganism and promotes mass loss of both natural and synthetic components of PU.

Moreover, polysaccharides could also be blended to different synthetic polymers such as polyvinyl alcohol (PVA) and polyacrylic acid (PAA) to synthesize bio-artificial polymeric materials as presented by Cascone et al. ${ }^{[19]}$ Dextran and chitosan are used as a drug delivery tool to modulate the release of growth hormone. Moreover, D-lactose is a compound with eight hydroxyl groups which could be used as difunctional monomer by utilizing the difference in reactivity between the primary and secondary hydroxyl groups. Donnelly et al. ${ }^{[20]}$ carried out synthesis of co-polyurethane based on mixture of commercial polydiols with glucose. Furthermore, Galbis and his group ${ }^{[21]}$ reported the use of xylitol, D-mannitol and L-arabitol for the preparation of polyurethane by polycondensation in solution with MDI. The PU with higher content of D-mannitol sugar is the most hydrophilic and is fastest to be degraded. They are applicable as redox-responsive carriers to modulate glutathione response. Lately, there is a patent which claims to achieve partially substituted sugar-based polyurethane ${ }^{[22]}$ with the use of polyether polyol. Sugars are simple carbohydrates which possess similar chemical structural properties like dicarboxylic acids which have previously shown representative results as a sole component in polyurethane.

The goal of this work is to perform theoretical study on sugars as the sole polyol component in polyurethane synthesis. Thus, the urethane bond formation between selected sugars and methylene diisocyanates (MDI) are examined by their potential to react with 4,4-MDI via their hydroxyl groups. The results are verified with laboratory experiments by synthesizing the most promising sugarbased PU. Ultimately, the work can contribute to the design of more environmental friendly polyurethanes for future industrial use.

\section{EXPERIMENTAL}

The reactivity of the structures (Table 1) was compared by exploring the potential energy surface of the reactions between the studied carbohydrates and an isocyanate model using density functional theory. The geometry of the reactants and the products were optimized, yielding potential minima which allowed the determination of the harmonic vibration frequencies needed for calculating the thermodynamic properties. All of the geometry optimizations were carried out at the B3LYP/6-31G $(d, p)$ level of theory as it is implemented in the Gaussian 09 program ${ }^{[23]}$ package. Normal mode analysis was carried out on each optimized structure at the same level of theory.

\section{Transition State Search}

Transition state (TS) structures were determined by searching saddle points on the potential energy surface (PES) of the reactions. Transition states of the reactions were located using the B3LYP/6-31G(d,p) level of theory. The reactions were analyzed by calculating the thermodynamic properties as well. The reactivity of the five different sugars, glucose, sucrose, fructose, maltose, mannitol towards the isocyanate model was compared by using the corresponding barrier heights of the possible reactions. 
Table 1. Structures of the sugar molecules and the used phenyl-isocyanate model. The number of possible reactions (number of free $\mathrm{OH}$ groups) is also shown by the numerical indication in red. The letter codes A, B, C, D, E are short notation for fructose, glucose, mannitol, maltose, sucrose, respectively. A1 denotes the hydroxyl group of fructose at position 1 and represent the corresponding reaction of the studied isocyanate with this hydroxyl group

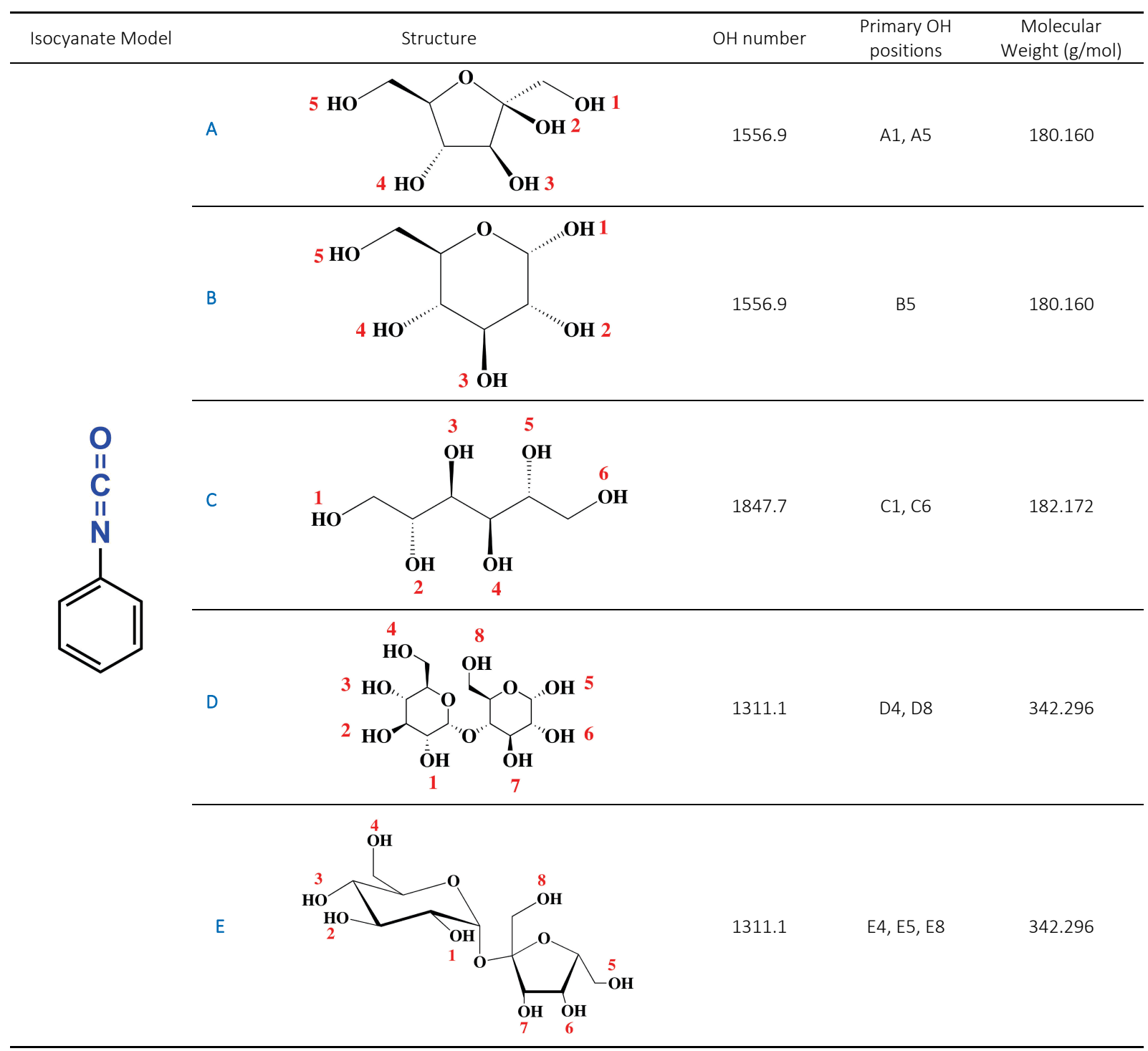

\section{RESULTS AND DISCUSSIONS}

\section{Sugar-Based Urethane Formation}

The reactants of each reaction are used as a reference while the products and the transition states are compared to them accordingly. The unstable transition state structures are formed when reactants reached the top of the energy, a high energy state structure which can easily turn into product or back to reactant. The structural and thermodynamic properties of the transitions states were analyzed.

\section{Structural Effects on Stability and Reactivity}

The spontaneity of the reaction depend on multiple chemical and physical factors, such as the barrier heights (relative Gibbs free energies) of the transition state complexes. Such factors are the distance between reacting atoms, the attack angle, and other inter-/intramolecular interactions which are intertwined with the reactivity of any reactions. Selected structural properties, the bond length of $\mathrm{O}-\mathrm{H}, \mathrm{C}-\mathrm{O}$ and $\mathrm{N}-\mathrm{H}$, and the bond angle $(\alpha)$ between $\mathrm{N}-\mathrm{C}-\mathrm{O}$ atoms, are collected in Table 2. During the 
Table 2. Structural properties of the transition states leading to urethane bond formation described by collecting the bond length of $\mathrm{O}-\mathrm{H}, \mathrm{C}-\mathrm{O}$ and $\mathrm{N}-\mathrm{H}$, and the bond angle $(\alpha)$ formed between $\mathrm{N}-\mathrm{C}-\mathrm{O}$. These geometrical parameters define the urethane bond formation from the $\mathrm{OH}$ group of the sugar and the corresponding isocyanate. The structures were optimized at the B3LYP/6-31G(d) level of theory. The OH group from the sugar polyol is depicted in red, and the NCO part of isocyanate is depicted in blue

\begin{tabular}{|c|c|c|c|c|}
\hline & O-H (Å) & $C-O(\AA)$ & $\mathrm{N}-\mathrm{H}(\AA ̊)$ & $\alpha(\mathrm{N}-\mathrm{C}-\mathrm{O})\left({ }^{\circ}\right)$ \\
\hline $\mathrm{A} 1$ & 1.16795 & 1.21107 & 1.40143 & 94.274 \\
\hline $\mathrm{A} 2$ & 1.19953 & 1.74730 & 1.31216 & 88.616 \\
\hline A3 & 1.17657 & 1.60262 & 1.38267 & 93.254 \\
\hline A4 & 1.18447 & 1.67949 & 1.33973 & 91.013 \\
\hline A5 & 1.17848 & 1.66950 & 1.34851 & 91.236 \\
\hline B1 & 1.20022 & 1.76624 & 1.32043 & 88.631 \\
\hline B2 & 1.16758 & 1.59729 & 1.38857 & 93.411 \\
\hline B3 & 1.16928 & 1.58898 & 1.38900 & 93.696 \\
\hline B4 & 1.17325 & 1.65828 & 1.35709 & 91.997 \\
\hline B5 & 1.17311 & 1.65039 & 1.35712 & 91.794 \\
\hline $\mathrm{C} 1$ & 1.16052 & 1.58583 & 1.38898 & 94.031 \\
\hline $\mathrm{C} 2$ & 1.18542 & 1.63320 & 1.35385 & 92.222 \\
\hline C3 & 1.17805 & 1.66869 & 1.34299 & 90.563 \\
\hline $\mathrm{C} 4$ & 1.17984 & 1.65782 & 1.35805 & 90.989 \\
\hline C5 & 1.18658 & 1.66928 & 1.35680 & 91.382 \\
\hline C6 & 1.18224 & 1.69795 & 1.34066 & 90.567 \\
\hline D1 & 1.17425 & 1.62781 & 1.39017 & 92.843 \\
\hline D2 & 1.16837 & 1.58100 & 1.39357 & 93.960 \\
\hline D3 & 1.20997 & 1.78800 & 1.30964 & 87.981 \\
\hline D4 & 1.16779 & 1.61781 & 1.37037 & 93.016 \\
\hline D5 & 1.16937 & 1.65347 & 1.38027 & 92.210 \\
\hline D6 & 1.21167 & 1.78278 & 1.30835 & 88.289 \\
\hline D7 & 1.15117 & 1.61474 & 1.39554 & 92.834 \\
\hline D8 & 1.18159 & 1.65996 & 1.34791 & 91.373 \\
\hline E1 & 1.15483 & 1.63872 & 1.40337 & 91.928 \\
\hline E2 & 1.16897 & 1.63218 & 1.36723 & 92.522 \\
\hline E3 & 1.17237 & 1.58041 & 1.39558 & 94.019 \\
\hline E4 & 1.16178 & 1.59669 & 1.38582 & 93.388 \\
\hline E5 & 1.18068 & 1.67332 & 1.34617 & 91.113 \\
\hline E6 & 1.17898 & 1.65374 & 1.36646 & 91.850 \\
\hline E7 & 1.18422 & 1.69546 & 1.34979 & 90.600 \\
\hline E8 & 1.17126 & 1.59161 & 1.40114 & 93.233 \\
\hline
\end{tabular}

urethane bond formation of fructose-PU, the $\mathrm{C}-\mathrm{O}$ bond distance is the shortest of around 1.21 $\mathrm{A}$. This corresponds to the movement of the hydrogen in the sugar polyol to the nitrogen of the isocyanate group. The bond distance in the 
Table 3. Barrier heights $\left(\Delta_{0} G^{\ddagger}\right)$ and reaction Gibbs free energies $\left(\Delta_{0} G_{r}\right)$ of urethane bond formation reactions between the studied sugars (sucrose, maltose, glucose, mannitol and fructose) and phenyl isocyanate in $\mathrm{kJ} / \mathrm{mol}$ calculated at the B3LYP/6-31G(d) level of theory

\begin{tabular}{|c|c|c|c|}
\hline Sugar & $\begin{array}{c}\text { Hydroxyl } \\
\text { Groups }\end{array}$ & $\begin{array}{c}\Delta_{0} G^{\ddagger} \\
(\mathrm{kJ} / \mathrm{mol})\end{array}$ & $\begin{array}{c}\Delta_{0} G_{r} \\
(\mathrm{~kJ} / \mathrm{mol})\end{array}$ \\
\hline \multirow{5}{*}{ A. Fructose } & 1. & 135.6 & -63.7 \\
\hline & 2. & 177.8 & 0.9 \\
\hline & 3. & 163.8 & -27.7 \\
\hline & 4. & 161.4 & -38.1 \\
\hline & 5. & 143.9 & -52.8 \\
\hline \multirow{5}{*}{ B. Glucose } & 1. & 147.9 & -46.4 \\
\hline & 2. & 151.4 & -50.5 \\
\hline & 3. & 152.6 & -50.3 \\
\hline & 4. & 142.2 & -57.0 \\
\hline & 5. & 158.2 & -41.3 \\
\hline \multirow{6}{*}{ C. Mannitol } & 1. & 152.7 & -46.7 \\
\hline & 2. & 174.0 & -11.1 \\
\hline & 3. & 187.5 & -3.3 \\
\hline & 4. & 176.2 & -3.3 \\
\hline & 5. & 172.9 & -9.0 \\
\hline & 6. & 148.7 & -45.0 \\
\hline \multirow{8}{*}{ D. Maltose } & 1. & 155.2 & -37.4 \\
\hline & 2. & 171.9 & -31.6 \\
\hline & 3. & 175.9 & -4.7 \\
\hline & 4. & 192.4 & -24.7 \\
\hline & 5. & 173.6 & -13.4 \\
\hline & 6. & 169.2 & -20.3 \\
\hline & 7. & 180.5 & -30.2 \\
\hline & 8. & 152.9 & -41.3 \\
\hline \multirow{8}{*}{ E. Sucrose } & 1. & 179.1 & -31.6 \\
\hline & 2. & 169.2 & -22.2 \\
\hline & 3. & 158.4 & -36.8 \\
\hline & 4. & 162.4 & -45.0 \\
\hline & 5. & 157.7 & -39.6 \\
\hline & 6. & 170.8 & -13.9 \\
\hline & 7. & 166.8 & -16.4 \\
\hline & 8. & 169.9 & -13.9 \\
\hline
\end{tabular}

reactant of fructose is less than $1 \AA$ while the $\mathrm{OH}$ group in the transition state complex has a bond distance more than $1 \AA$ A as slowly disintegrates when $\mathrm{H}$ moves further to form a bond with nitrogen. Moreover, all the atoms involved in the urethane bond forming reactions are interacting on the same horizontal plane. The angle formed between $\mathrm{N}-\mathrm{C}-\mathrm{O}$ is close to $90^{\circ}$ as shown in Table 2 . The atoms involved in the reaction formed a quadrilateral plane which is stable for the transition state complex due to multiple secondary interactions. There is no direct relation between the angle and the spontaneity of the reaction, but it provides a clear visualization of a stabilized complex. In general, the trend can be observed for all sugar polyols.

\section{Energetic Properties of Urethane Formation}

In the case of the most preferred reaction channel of the sugars the transition state has the lowest barrier height (relative Gibbs free energy, $\Delta_{0} G^{\ddagger}$ ). The $\Delta_{0} G^{\ddagger}$ of each urethane reaction of every sugar-PU collected in Tables 3 and 4 . The numbering of the structures is based on the numbering of the hydroxyl groups in the sugars. Thus, A1 denotes the hydroxyl group of fructose at position 1 and represent the corresponding reaction of the studied isocyanate with this hydroxyl group (Table 1 and Table 3).

The urethane bond formation of A1 has the lowest barrier height within the studied set of fructose-PU reactions $(135.6 \mathrm{~kJ} / \mathrm{mol})$. It is also the lowest among the five sugars, indicating higher reactivity compare to the other species. Fructose has two primary hydroxyl groups and a pentane ring that stabilize the transition state complex. By observing the structures, the hydrogen from the hydroxyl group is moving toward the nitrogen to form urethane linkage. If there is no stabilization in the system, the complex can disintegrate back to reactants instead of forming new urethane bond as a product. Moreover, the transition state complex for fructose-based polyurethane is the least favorable for A2 within the fructose set. It is a reaction with a tertiary hydroxyl group pointing out. Thus, it is highly steric hindered which makes the urethane bond unlikely to form at that position as evident in the positive value of reaction Gibbs free energy $0.9 \mathrm{~kJ} / \mathrm{mol}$.

The formation of urethane linkage during polymerization is dependent on primary $\mathrm{OH}$ reaction and stereoselectivity. Several experimental studies in literature showed corresponding results. Kong et al.[24,25] found that the gel time for Liprol-270-MDI PU formation is 20 minutes while it is 100 minutes for Liprol-320-MDI PU formation. Liprol-270 contained both primary and secondary hydroxyl groups when 1,2-propanediol was used instead of 1,3propanedial. Moreover, Luo et al. ${ }^{[26]}$ showed that the polyol reacts faster due to reduced gelation time when Agrol Diamond $^{\circ}$, a natural polyol with more primary hydroxyl group, is added. Furthermore, the position of the hydroxyl groups interferes with the bulky rings which affect the angle of nucleophilic attack during the urethane bond formation. Maltose-PU and sucrose-PU showed the highest energy barrier (lowest reactivity) of $152.9 \mathrm{~kJ} / \mathrm{mol}$ and 157.7 $\mathrm{kJ} / \mathrm{mol}$, respectively. Moreover, molecular weight of the polyol plays a role on the flexibility of polyurethane. The transition state energies of maltose-PU and sucrose-PU are 
Table 4. Summary of the the most preferred channel for each sugar-based polyurethane reaction. The barrier heights $\left(\Delta_{0} G^{\ddagger}\right)$ and reaction Gibbs free energies $\left(\Delta_{0} G_{r}\right)$ are shown

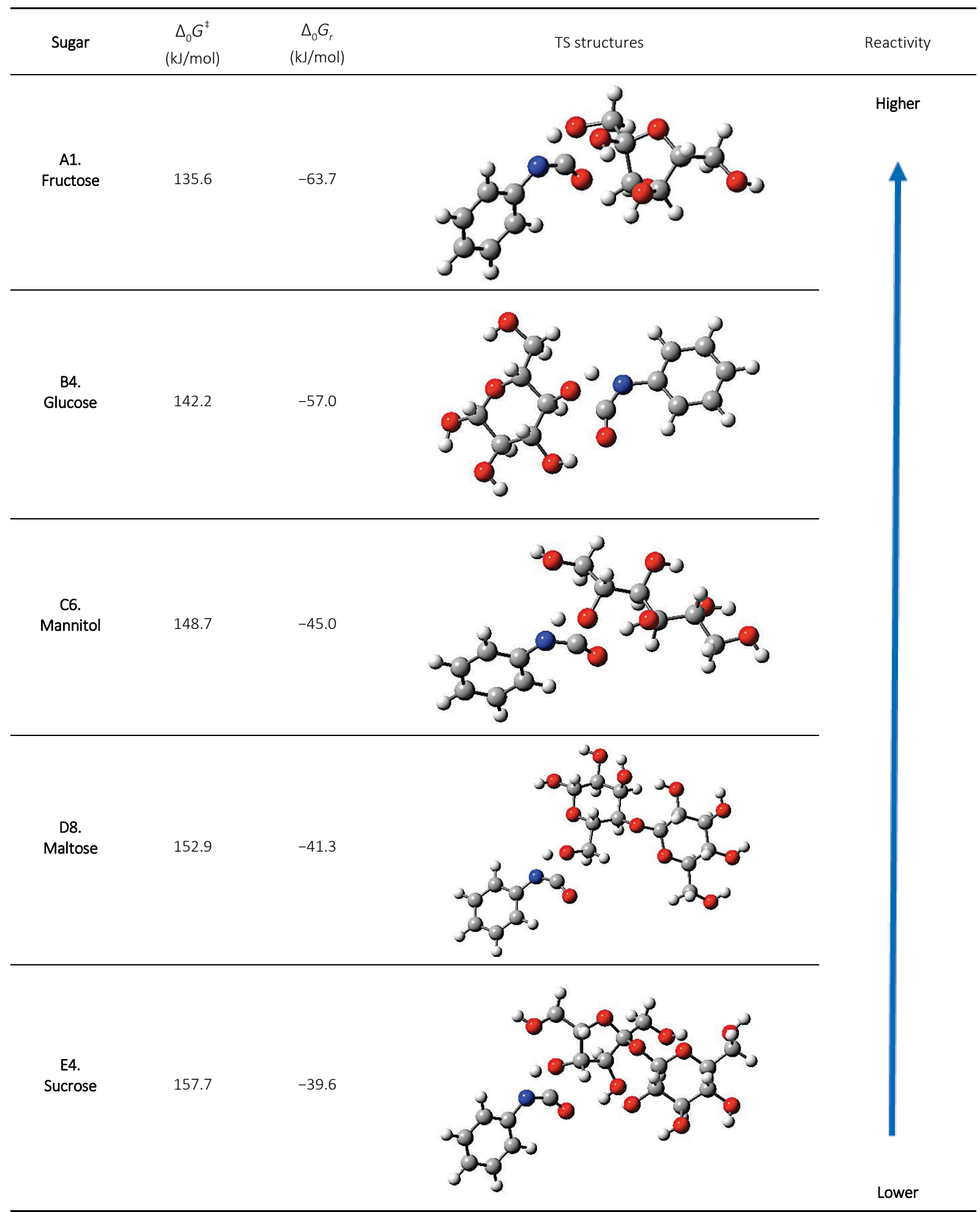

similar because of similar chemical and structural properties. Likewise, the same result is observed for
glucose-PU and sucrose-PU as their functionality is similar, as well their molecular weight and $\mathrm{OH}$ number is identical. 


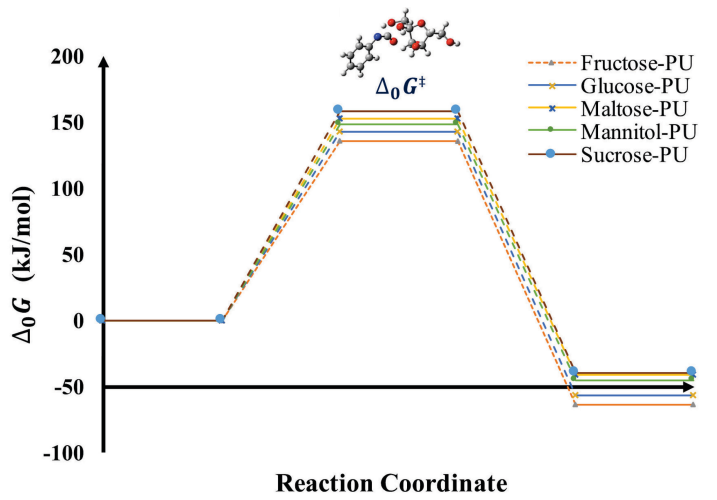

Figure 2. The reaction energy profile of urethane bond formation between the most reactive hydroxyl groups studied sugars (sucrose, maltose, glucose, mannitol and fructose) and phenyl isocyanate. The transition state complex of A1-fructose and the barrier are shown. The thermodynamic parameters were calculated at the B3LYP/6-31G(d) level of theory.

Furthermore, it is found that flexible nature of the foam is enhanced with increasing molecular weight. ${ }^{[27]}$ The formation of urethane bond is exergonic in nature. Evidently, the reaction Gibbs free energy for fructose-PU is the lowest $-63.7 \mathrm{~kJ} / \mathrm{mol}$ and largest for sucrose-PU -39.6 $\mathrm{kJ} / \mathrm{mol}$. A schematic diagram for the reaction coordinate of sugar-based PU reactions is shown in Figure 2. Evidently, a lower transition state energy and more negative the reaction Gibbs free energy contribute to the formation of urethane bond.

\section{Macroscopic Observations of Sugar- Based Polyurethanes}

The positive results obtained from the calculations have encouraged the synthesis of fructose-based polyurethane foam. The isocyanate used in this research is commercialized Ongronat $^{\circledR} 2100$ kindly supplied by BorsodChem $\mathrm{Zrt}$. It is composed of $\mathrm{MDI}$ with highly reactive NCO groups at 4,4 positions. It is chosen because aromatic isocyanates are more reactive than aliphatic one. $\mathrm{N}, \mathrm{N}$ Dimethyl formamide (DMF) was the only solvent used to dissolve sugar particles. The fructose-PU foam was synthesized at room temperature by reacting " $A$ "-side with " $\mathrm{B}$ "-side in a two-step reaction. " $\mathrm{A}$ "-side is the fructose solution, containing $4 \mathrm{~g}$ of fructose in $10 \mathrm{~mL}$ of DMF with additional water and catalyst, while the " $B$ "-side is the Ongronat ${ }^{\circledR} 2100$ isocyanate. After mixing " $A$ "-side with " $B$ "side the foam was able to freely rise up to $13 \mathrm{~cm}$ without collapsing. The foam was stable with minimal sign of shrinkage (Figure 3). It can be observed that characteristic PU bonds appeared in the prepared fructose-based

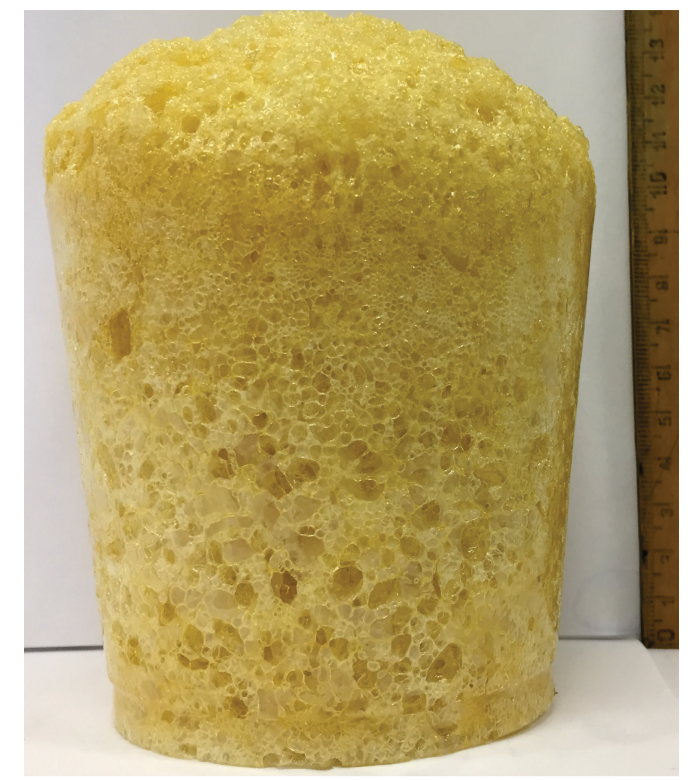

Figure 3. Photo of the fructose-based polyurethane foam.

samples (Figure 4). The sample show signs of $\mathrm{N}-\mathrm{H}$ stretching and bending vibration absorptions at $3320 \mathrm{~cm}^{-1}$ and 1530 $\mathrm{cm}^{-1}$. Furthermore, $\mathrm{C}=\mathrm{O}$ stretching vibration occur at 1650 and $1708 \mathrm{~cm}^{-1}$, and $\mathrm{C}-\mathrm{N}$ vibration at $1600 \mathrm{~cm}^{-1}$. During the synthesis, the reaction occurred vigorously when the sugar and isocyanate were stirred. It produced carbon dioxide and heat during the foam formation. This is in correlation with the exothermicity of the reaction as shown in the reaction energy profile in Figure 2.

\section{CONSLUSIONS}

The reaction mechanisms for urethane bond formation between five sugars were modelled with density functional theory. Reactivity is preferred for lower transition state energy barrier and lower Gibbs free energies of reaction. Moreover, position of $\mathrm{OH}$ groups affects the angle of attack. Thus, primary $\mathrm{OH}$ groups are preferred due to steric hindrance. Consequently, polyols with more primary $\mathrm{OH}$ groups have better reactivity as shown in both theoretical and experimental study. Nevertheless, the properties of foam depend on the balance of chemical properties and structural properties of polyols. Fructose-isocyanate reaction was found to have the lowest barrier height of $135.6 \mathrm{~kJ} / \mathrm{mol}$ and lowest Gibbs free energy of reaction $-63.7 \mathrm{~kJ} / \mathrm{mol}$. Therefore, the results obtained from the calculations have encouraged the synthesis of fructosebased polyurethane foam. The synthesis was successful, and the produced fully fructose-based foam was stable with minimal sign of shrinkage. This exothermic reaction proceeds rapidly with the foam achieving $13 \mathrm{~cm}$ in height 


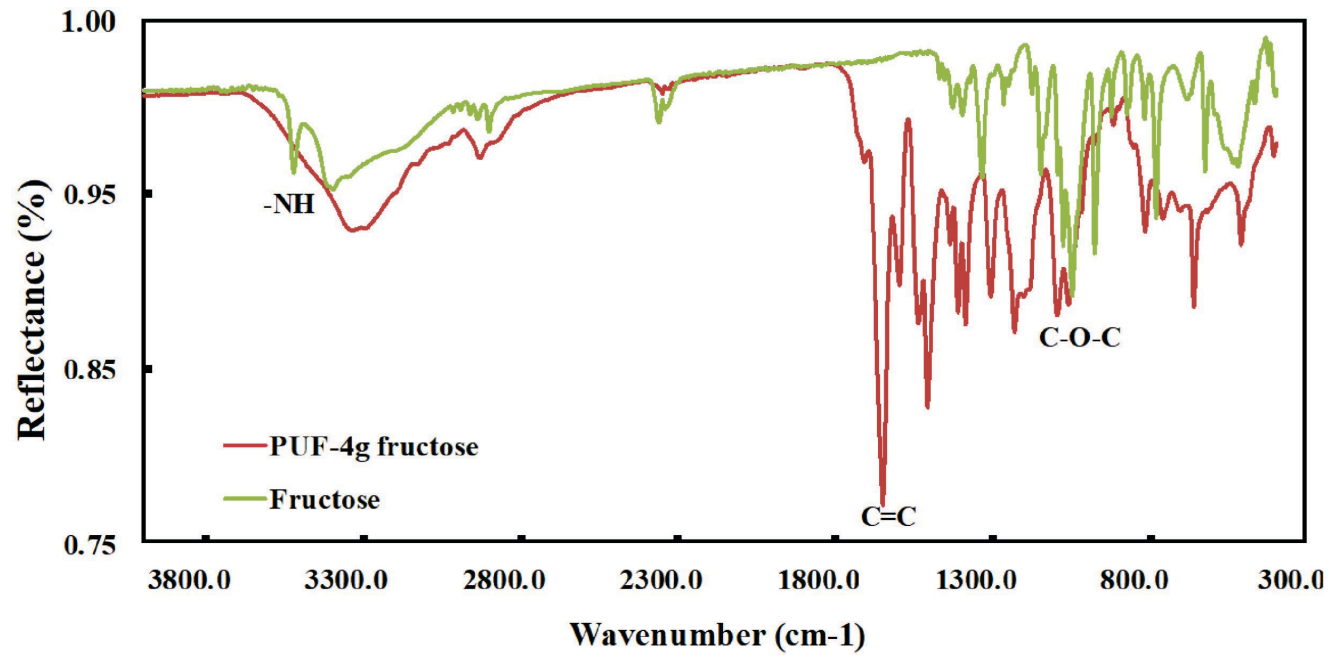

Figure 4. Fourier-transform infrared spectra of the prepared fructose-based polyurethane foam (red line). The spectra of pure fructose (green line) also depicted for comparative purposes.

when expands freely in lab. Thus, a novel synthesis of sugar-based PU foams was designed which involves sugar as the sole polyol component in polyurethane foams. This study provides insights into the effective cooperation between computational and experimental techniques to design environmental friendly polymers.

Acknowledgment. We thank Máté Labádi and Dr. Dávid Vincze for the administration of the Herkules computing cluster (University of Miskolc) used in this work. This research was supported by the European Union and the Hungarian State, co-financed by the European Regional Development Fund in the framework of the GINOP-2.3.415-2016-00004 project, aimed to promote the cooperation between the higher education and the industry. BF thanks the support by the New National Excellence Program of the Ministry of Human Capacities (HU) under the ÚNKP-17-4-I$\mathrm{ME} / 17$ project. Furthermore, the generous support from the Institute of Chemistry, University of Miskolc is gratefully acknowledged.

\section{REFERENCES}

[1] E. Sharmin, F. Zafar, Polyurethane: An Introduction, 2012, pp. 3-16.

[2] G. T. Howard, Biodegradation of Polyurethane: $A$ Review. In International Biodeterioration and Biodegradation, 2002, Vol. 49, p. 245.

[3] O. Figovsky, Green Nanostructured Biodegradable Materials Short Review Part I. 2016, 1, 2007.

[4] O. Figovsky, A. Leykin, L. Shapovalov, Chem. Chem. Technol. 2016, 10(4), 553.

[5] M. E. Jazi, T. Al-Mohanna, F. Aghabozorgi, Glob. J. Sci. Front. Res. B Chem. 2016, 16(3), 120.
[6] G. Rokicki, P. G. Parzuchowski, M. Mazurek, NonIsocyanate Polyurethanes: Synthesis, Properties, and Applications. Polymers for Advanced Technologies, 2015, pp. 707-761.

[7] H. Tomita, F. Sanda, T. Endo, J. Polym. Sci. Part A Polym. Chem. 2001, 39(23), 4091.

[8] M. S. Kathalewar, P. B. Joshi, A. S. Sabnis, V. C. Malshe, RSC Adv. 2013, 3(13), 4110.

[9] L. Ugarte, A. Saralegi, R. Fernández, L. Martín, M. A. Corcuera, A. Eceiza, Ind. Crops Prod. 2015, 62, 545.

[10] C. K. Patil, S. D. Rajput, R. J. Marathe, R. D. Kulkarni, H. Phadnis, D. Sohn, P. P. Mahulikar, V. V. Gite, Prog. Org. Coatings 2017, 106, 87.

[11] T. Travinskaya, Y. Savelyev, E. Mishchuk, Polym. Degrad. Stab. 2014, 101(1), 102.

[12] X. Cao, L. Zhang, J. Huang, G. Yang, Y. Wang, J. Appl. Polym. Sci. 2003, 90(12), 3325.

[13] M. Oliviero, L. Verdolotti, M. Stanzione, M. Lavorgna, S. Iannace, M. Tarello, A. Sorrentino, J. Appl. Polym. Sci. 2017, 134(45), 45113.

[14] X. Zhang, K. G. Battiston, J. E. McBane, L. A. Matheson, R. S. Labow, J. P. Santerre, Design of Biodegradable Polyurethanes and the Interactions of the Polymers and Their Degradation By-Products Within in Vitro and in Vivo Environments. In Advances in Polyurethane Biomaterials, 2016, pp. 75-114.

[15] J. David, L. Vojtová, K. Bednařík, J. Kučerík, M. Vávrová, J. Jančář, Environ. Chem. Lett. 2010, 8(4), 381.

[16] Ö. Güngör, A. Pasąhan, M. A. Cengiz, S. Koÿtepe, T. Seçkin, Int. J. Polym. Mater. Polym. Biomater. 2015, 64(11), 563. 
[17] O. Ciferri, Microbial Degradation of Paintings. Applied and Environmental Microbiology, 1999, $\mathrm{p}$ 879.

[18] Y. Savelyev, L. Markovskaya, O. Savelyeva, E. Akhranovich, N. Parkhomenko, T. Travinskaya, J. Appl. Polym. Sci. 2015, 132(25), 42131.

[19] M. G. Cascone, N. Barbani, C. Cristallini, P. Giusti, G. Ciardelli, L. Lazzeri, Journal of Biomaterials Science, Polymer Edition. 2001, p. 267.

[20] B. Begines, F. Zamora, I. Roffé, M. Mancera, J. A. Galbis, J. Polym. Sci. Part A Polym. Chem. 2011, 49(9), 1953.

[21] M. V. De Paz, F. Zamora, B. Begines, C. Ferris, J. A. Galbis, Biomacromolecules 2010, 11(1), 269.

[22] J. Mooney, Sugar-Based Polyurethanes, Methods for Their Preparation, and Methods of Use Thereof. US20130030067 A1, 2013.
[23] M. J. Frisch, G. W. Trucks, H. B. Schlegel, G. E. Scuseria, M. A. Robb, J. R. Cheeseman, G. Scalmani, V. Barone, B. Mennucci, G. A. Petersson, H. Nakatsuji, M. Caricato, X. Li, H. P. Hratchian, A. F. Izmaylov, J. Bloino, G. Zheng, D. J. Sonnenber, Gaussian 09. Gaussian, Inc. Wallingford CT 2009, 2-3.

[24] X. Kong, G. Liu, J. M. Curtis, Eur. Polym. J. 2012, 48(12), 2097.

[25] X. Kong, L. Zhao, J. M. Curtis, Carbohydr. Polym. 2016, 152, 487.

[26] N. Luo, J. Qian, J. Cupps, Y. Wang, B. Zhou, L. Armbruster, P. Frenkel, Natural Oil Polyol of High Reactivity for Rigid Polyurethanes, BioBased Technol. 2007.

[27] L. Zhang, Structure-Property Relationship of Polyurethane Flexible Foam Made from Natural Oil Polyols. PhD Diss. 2008, 1-208. 